Research Article

\title{
Determination of Cyclic Filling Length in Gob-Side Entry Retained with Roadside Filling and Its Application
}

\author{
Zizheng Zhang $\mathbb{D}^{1,2}$ Jinlin Xin, ${ }^{2}$ Jianbiao Bai, ${ }^{3}$ Xianyang Yu $\mathbb{D}^{2},{ }^{2}$ Weijian Yu $\left(\mathbb{D},{ }^{2}\right.$ \\ and Min Deng \\ ${ }^{1}$ State Key Laboratory of Mining Response and Disaster Prevention and Control in Deep Coal Mines, \\ Anhui University of Science and Technology, Huainan 232001, China \\ ${ }^{2}$ Key Laboratory of Coal Mine Gas and Roof Disaster Prevention and Control, Hunan University of Science and Technology, \\ Xiangtan, Hunan 411201, China \\ ${ }^{3}$ State Key Laboratory of Coal Resources and Safe Mining, China University of Mining and Technology, Xuzhou 221116, China \\ Correspondence should be addressed to Zizheng Zhang; hnustzzz@hnust.edu.cn
}

Received 15 April 2021; Accepted 7 August 2021; Published 16 September 2021

Academic Editor: Junfei Zhang

Copyright (C) 2021 Zizheng Zhang et al. This is an open access article distributed under the Creative Commons Attribution License, which permits unrestricted use, distribution, and reproduction in any medium, provided the original work is properly cited.

\begin{abstract}
Gob-side entry retained with roadside filling (GER-RF) plays a key role in achieving coal mining without pillar and improving the coal resource recovery rate. Since there are few reports on the cyclic filling length of GER-RF, a method based on the stress difference method is proposed to determine the cyclic filling length of GER-RF. Firstly, a stability analysis mechanics model of the immediate roof above the roadside filling area was established, and then, the relationship between the roof stress distribution and the unsupported roof length was obtained by the stress difference method. According to the roof stability above the roadside filling area based on the relationship between the roof stress and its tensile strength, the maximum unsupported roof length and rational cyclic filling length were determined. Combined with the geological conditions of the 1103 thin coal seam working face of Heilong Coal Mine and the 1301 thick coal seam working face of Licun Coal Mine, the suggested method was applied to determine that the rational cyclic filling lengths were $2.4 \mathrm{~m}$ and $3.2 \mathrm{~m}$, respectively. Field trial tests show that the suggested method can effectively control the surrounding rock deformation along with rational road-in support and roadside support and improve the filling and construction speed.
\end{abstract}

\section{Introduction}

1.1. Literature Review of GER-RF. In recent years, gob-side entry retained (GER) without coal pillar mining technology has its advantages. These advantages include alleviating the contradiction of excavation replacement, improving coal recovery rate, realizing working face Y-type ventilation, and solving corner gas accumulation. GER has been developed into one of the green, safe, and efficient mining technologies for coal resources [1-4]. Since the 1950s, China and other major coal-producing countries have carried out many industrial tests of GER. Deng proposed a GER case in the medium-thick coal seam of the Lvshuidong Coal Mine [5]. Zhang et al. proposed a GER case in thin seam with large inclined angle [6]. He proposed an approach for a GER case in thick coal seam long wall mining [7]. Ning proposed a GER case with a "coal-backfill-gangue" support system in the thin coal seam $(1.3 \mathrm{~m})$ of Binhu Coal Mine [8]. Luan proposed a GER case with thick and hard roof in the thin coal seam $(1.25 \mathrm{~m})$ of Dongtan Coal Mine [9]. Wang proposed a nopillar mining technique with automatically formed GER in the thick coal seam $(4.11 \mathrm{~m})$ of Ningtiaota Coal Mine [10]. Huang et al. proposed a GER case using a concretefilled steel tubular column as roadside supporting in the thin coal seam $(1.15 \mathrm{~m})$ [11]. Ma et al. proposed a GER case in the medium-thick coal seam of the Tashan Coal Mine [12]. Zhang proposed a GER case in the medium-thick coal seam $(2.8 \mathrm{~m})$ of Xinyuan Coal Mine [13]. Therefore, GER engineering applications have developed from thin 
coal seam and medium-thick coal seam to thick coal seam mining. The GER technology with roadside filling is one of the widely used GER technologies. When the roadside filling is carried out, the roadside filling body generally lags behind the end support of the working face. The filling area near the roadway is often in the state of no support or simple temporary support; that is, the support strength of the area to be filled is low, which is called "lagging unsupported roof" (see Figure 1). Zhang et al. and Zheng and Bai firstly proposed that roof stability in the filling area is one of the key factors for the success of GER $[14,15]$. The length of the lagging unsupported roof in GER-RF is mainly composed of the cyclic filling length and the width of the pedestrian passage behind the support [16]. The width of the pedestrian passage is generally $0.8 \mathrm{~m}$. Therefore, the cyclic filling length in GER-RF is the bottleneck to improve the construction speed of the roadside filling body.

\subsection{Literature Review of the Cyclic Filling Length in GER-RF.} At present, the daily mining length of the high-efficiency fully mechanized mining working face in China is usually more than $4.8 \mathrm{~m}$. Due to the early strength performance, solidification time, and resistance increasing speed of existing filling materials $[1,2,9,10]$, the roadside filling body may not be constructed in time or the built roadside filling body cannot reach the designed support resistance in time and the length of the lagging unsupported roof will increase. When the length of the lagging unsupported roof is too large, the lower part of the immediate roof may lose stability under the action of tensile stress. Therefore, how to determine the rational cyclic filling length in GER-RF is very important to match the daily mining length of the high-efficiency fully mechanized mining working face. However, the cyclic filling length was manually determined previously, and there are no published reports at home and abroad on the determination method and theory of the cyclic filling length in GER-RF.

This paper presents a method to determine the length of the lagging unsupported roof and the cyclic filling length in GER-RF. Firstly, the mechanical model of the immediate roof stability analysis above the roadside filling area in GER-RF is established. The relationship between the stress distribution of the immediate roof above the roadside filling area and the length of the lagging unsupported roof is calculated by means of the stress difference method. Then, the stability of the immediate roof above the roadside filling area in GER-RF is determined according to the comparison between the immediate roof stress and ultimate tensile strength. On the basis of this, the reasonable length of the lagging unsupported roof and the cyclic filling length in GER-RF are determined. Finally, the method is carried out in two different thickness coal seams (thin coal seam and thick coal seam) with high water materials roadside filling and GER engineering practice.

\section{Mechanical Model of Immediate Roof Stability Analysis above the Roadside Filling Area in GER-RF}

It is very important to determine the length of the lagging unsupported roof during the construction of the roadside filling body. When the length of the lagging unsupported roof is too large, the roof above the roadside filling area is prone to collapsing. When the length of the lagging unsupported roof is too small, the filling cycle times are more and the utilization rate of the filling body support is low. Under this condition, the construction speed of the roadside filling body is affected and the working efficiency of the high-efficiency fully mechanized mining working face is limited. The existing study shows that the lower strata of the immediate roof are in the range of tensile stress, and with the increase of the rotation subsidence angle of the main roof (the process of increasing the support resistance of the roadside filling body), the scope of the tensile stress gradually decreases. It can be seen that the roof of the area to be filled is mainly the tensile failure of the shallow immediate roof. The temporary support of the area to be filled and its surrounding is mainly to prevent the collapse of the immediate roof in the lagging unsupported roof area to be filled. In reality, the immediate roof above the roadside filling area in GER-RF is affected by the abutment pressure in front of the hydraulic support of the working face. The subsidence of the immediate roof gradually increases until the built roadside filling body starts to support the immediate roof. As a result, the cumulative damage of the immediate roof rock increases gradually. Therefore, the immediate roof of the area to be filled is the key to control surrounding rock during the filling period of GER-RF.

A large area of the suspended roof will form at the end of the working face before the filling body is built along the goaf. The immediate roof in the area to be filled may be in the stage of no support or low support strength, as shown in Figure 2(a). The roof is supported by the coal wall in front of the working face, the hydraulic support at the end, and the newly built backfill. Therefore, a mechanical model of immediate roof stability analysis above the roadside filling area in GER-RF is established, as shown in Figure 2(b). The main assumptions of the model are as follows: (1) the immediate roof can be regarded as a rock beam with the same support stress as the overburden pressure, roadside support force, end hydraulic support force, and abutment pressure in a certain range in front of the working face; (2) the pressure load above the immediate roof (including the weight of the immediate roof) is $q$, and below the immediate roof are the support loads provided or passively generated by the coal wall support section, the end hydraulic support section, and the roadside filling body section of the retaining roadway, respectively, which are $q_{1}, q_{2}$, and $q_{4}$, and the length of each corresponding segment is $L_{1}, L_{2}$, and $L_{4}$, respectively; (3) in the model, 


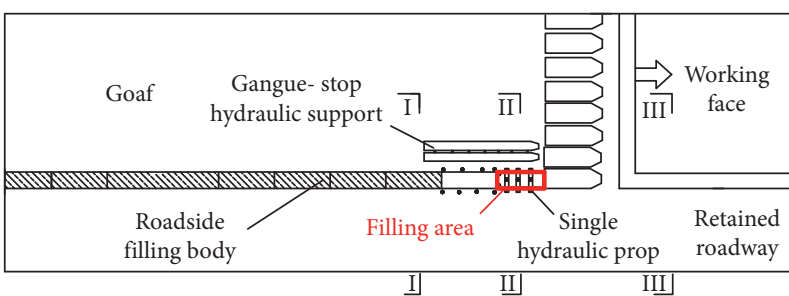

(a)

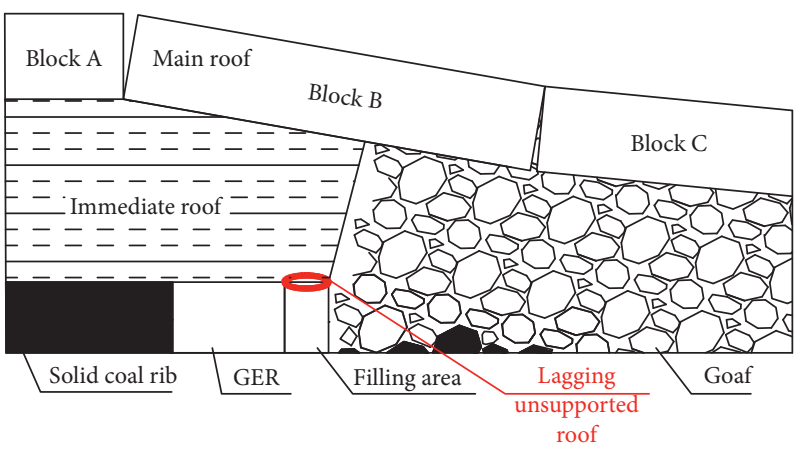

(c)

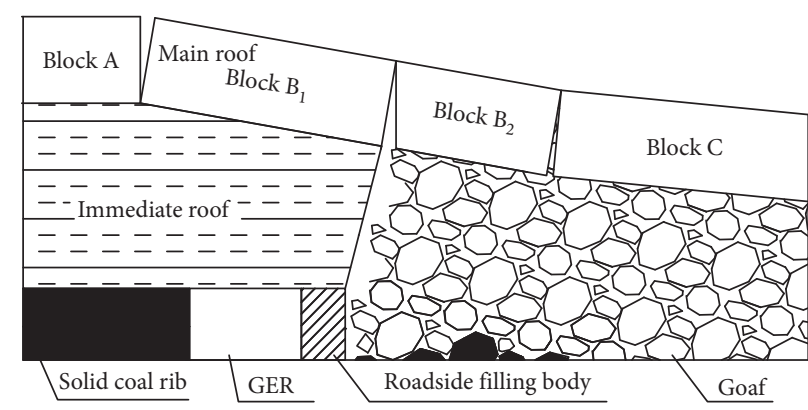

(b)

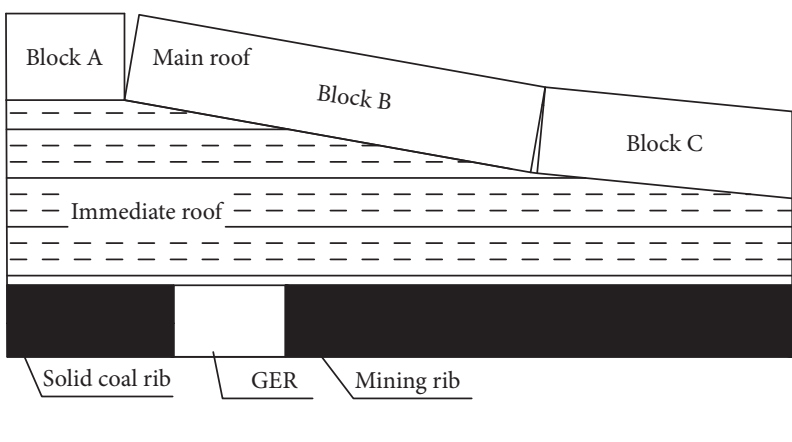

(d)

FIGURE 1: Sketch of lagging unsupported roof in GER-RF: (a) plan view of GER-RF, (b) section view of I-I, (c) section view of II-II, and (d) section view of III-III.

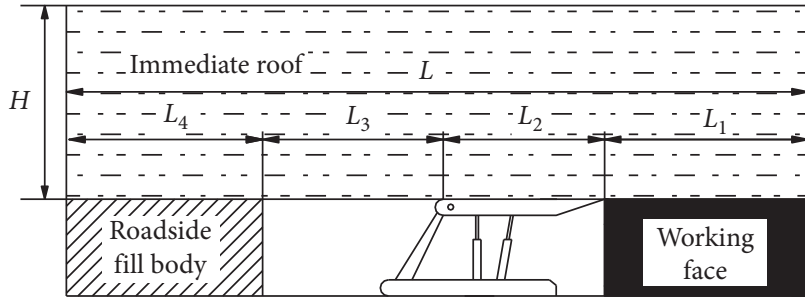

(a)

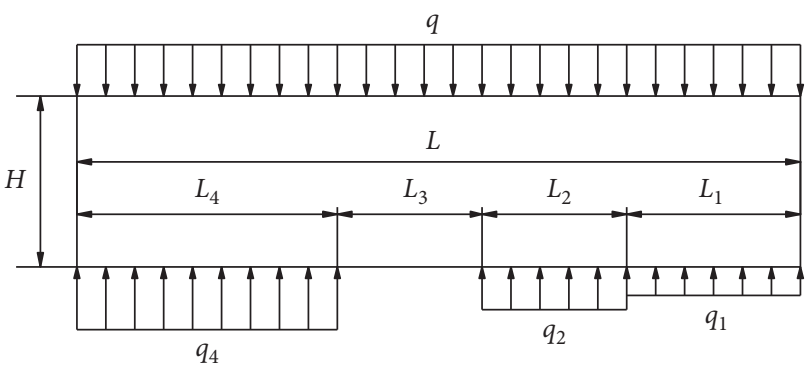

(b)

FIGURE 2: Mechanical model of immediate roof stability analysis above the roadside filling area in GER-RF. (a) Section of GER-BB along the strike direction. (b) Immediate roof mechanical model in GER-RF along the strike direction.

the sum of $L_{3}$ and $L_{4}$ is calculated according to the periodic weighting length of the main roof. (4) $L_{2}$ is the total length of the top beam of the hydraulic support; (5) $L_{1}$ is selected according to the position of the peak abutment pressure in front of the coal wall; and (6) the main roof is assumed to be rigid.

\section{Immediate Roof Stress Component Solution of the Roadside Filling Area Based on the Stress Difference Method}

The difference method is an approximate numerical solution of differential equations, including the stress difference method and displacement difference method. Specifically, the difference method is to replace the differential equation with a finite difference and the derivative with a finite difference quotient, so that the basic equation and boundary condition (generally differential equation) are approximately expressed by the difference equation (algebraic equation), and the problem of solving a differential equation is changed into the problem of solving an algebraic equation. In elastic mechanics, the difference method and the variational method are used to solve plane problems.

Taking the $5 \mathrm{~m}$ thick immediate roof as an example, when $L_{3}$ is $5.0 \mathrm{~m}$, the periodic weighting length $\left(L_{3}+L_{4}\right)$ is $15 \mathrm{~m}$, and the top beam length of the end bracket $\left(L_{2}\right)$ is $5 \mathrm{~m}$. $L_{1}$ is assumed to be $10 \mathrm{~m}$, namely, the total length $(L)$ is $30 \mathrm{~m}$. The difference grid of the immediate roof is divided along the roadway strike and vertical direction, with each grid length of $0.5 \mathrm{~m}$, as shown in Figure 3. The boundary load of 


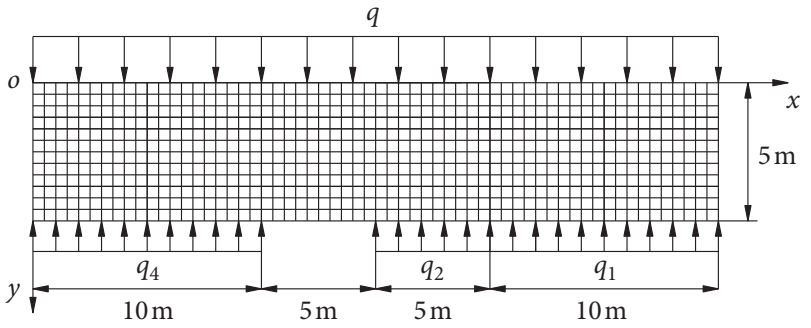

FIGURE 3: Finite difference elements of the immediate roof in GER-RF.

the model is applied. Then, the stress difference method is used to solve the stress component of the immediate roof of the retained roadway.

First of all, $q_{1}$ and $q_{4}$ are determined by the following formula according to the mechanical equilibrium:

$$
\left\{\begin{array}{l}
q L=q_{1} L_{1}+q_{2} L_{2}+q_{4} L_{4}, \\
\frac{1}{2} q L^{2}=\frac{1}{2} q_{1} L_{1}^{2}+\frac{1}{2} q_{2}\left[\left(L_{1}+L_{2}\right)^{2}-L_{1}^{2}\right] \\
+\frac{1}{2} q_{4}\left[L^{2}-\left(L_{1}+L_{2}+L_{3}\right)^{2}\right] .
\end{array}\right.
$$

Secondly, the stress difference method and software programming are used to solve the stress function of the immediate roof along the goaf $[17,18]$. Part of the model is taken for solution explanation (as shown in Figure 4). In Figure 4, the grid width in $x$ and $y$ directions is equal, $\mathrm{A}$ and $\mathrm{B}$ are nodes numbered, $\varphi$ is the stress function, and $\varphi_{i}$ represents the stress value with node number $i$.

The stress difference method is used to calculate the stress component of the immediate roof of the retained roadway $[17,18]$.

(1) A node is arbitrarily selected on the boundary as the base point.

$$
\varphi_{A}=\left(\frac{\partial \varphi}{\partial x}\right)_{A}=\left(\frac{\partial \varphi}{\partial y}\right)_{A}=0
$$

Then, the $\varphi$ value of all nodes on the boundary and the necessary value and value of formula (3) are calculated by the sum of the moment and surface force of the surface force, $\partial \varphi / \partial x$ and $\partial \varphi / \partial y$.

$$
\left\{\begin{array}{c}
\varphi_{13}=\varphi_{9}+2 h\left(\frac{\partial \varphi}{\partial x}\right)_{A} \\
\varphi_{14}=\varphi_{10}+2 h\left(\frac{\partial \varphi}{\partial y}\right)_{B}
\end{array}\right.
$$

The left side of the equation is the imaginary node outside the boundary, and the right side is the real node.

Thus, all recursive formulas that conform to the $\varphi$ values of all nodes are obtained.

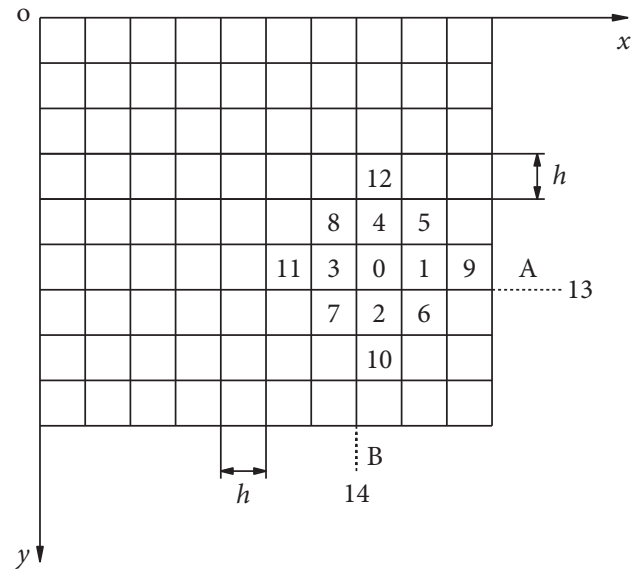

FIGURE 4: Schematic diagram of the stress difference method.

$$
\left\{\begin{array}{l}
\varphi_{2 i+1}=\varphi_{i}+2 h\left(\frac{\partial \varphi}{\partial x}\right)_{A} \\
\varphi_{2(i+1)}=\varphi_{2 i}+2 h\left(\frac{\partial \varphi}{\partial y}\right)_{B} .
\end{array}\right.
$$

(2) Formula (4) is applied to represent the $\varphi$ value of each virtual node on the boundary with the $\varphi$ value of the corresponding node within the boundary.

(3) At node 0 , the difference equation is

$$
\begin{aligned}
& 20 \varphi_{0}-8\left(\varphi_{1}+\varphi_{2}+\varphi_{3}+\varphi_{4}\right)+2\left(\varphi_{5}+\varphi_{6}+\varphi_{7}+\varphi_{8}\right) \\
& +\left(\varphi_{9}+\varphi_{10}+\varphi_{11}+\varphi_{12}\right)=0 .
\end{aligned}
$$

For each node in the boundary, such a difference equation can be established and solved simultaneously, so as to find out the value of each node.

(4) According to formula (4), we calculate the value of each virtual node in a row outside the boundary.

(5) The stress component is calculated according to the following equations:

$$
\begin{aligned}
\left(\sigma_{x}\right)_{0} & =\left(\frac{\partial^{2} \varphi}{\partial y^{2}}\right)_{0}=\frac{1}{h^{2}}\left[\left(\varphi_{2}+\varphi_{4}\right)-2 \varphi_{0}\right], \\
\left(\sigma_{y}\right)_{0} & =\left(\frac{\partial^{2} \varphi}{\partial x^{2}}\right)_{0}=\frac{1}{h^{2}}\left[\left(\varphi_{1}+\varphi_{3}\right)-2 \varphi_{0}\right], \\
\left(\tau_{x y}\right)_{0} & =\left(-\frac{\partial^{2} \varphi}{\partial y^{2}}\right)_{0}=\frac{1}{h^{2}}\left[\left(\varphi_{5}+\varphi_{7}\right)-\left(\varphi_{6}+\varphi_{8}\right)\right]
\end{aligned}
$$

Similarly, the stress components of other nodes can be obtained. Due to a large number of nodes, the simultaneous solution of multiple equations requires a large amount of computational work, which needs to be solved by programming software and in accordance with the abovementioned calculation steps. 


\section{Determination Method and the Realization Process of Cyclic Filling Length in GER-RF}

Based on the stress difference method, the method and realization process to determine the cyclic filling length in GER-RF are as follows:

(1) Firstly, according to the mining and geological conditions of the retained roadway, the mechanical model of immediate roof stability analysis above the roadside filling area in GER-RF was established and grid division was carried out.

(2) Then, the relevant parameters required in Section 2 are selected according to the mining and geological conditions of the retained roadway and the rock mechanics parameters of surrounding rocks.

(3) In view of different lengths of the lagging unsupported roof schemes, considering that the difference of each level of the length of the lagging unsupported roof is less than shearer cutting depth, we gradually increase the length of the lagging unsupported roof, calculate and solve, respectively, and obtain the corresponding maximum tensile stress.

(4) The maximum tensile stress under each scheme is recorded, and the relevant maximum tensile stress is compared with the immediate roof tensile strength above the roadside filling area under this scheme, so as to determine whether the maximum tensile stress under this scheme exceeds the immediate roof tensile strength and then determine the maximum length of the lagging unsupported roof in GER-RF.

(5) According to the maximum length of the lagging unsupported roof in GER-RF and the minimum width of the pedestrian passage, we determine the reasonable cyclic filling length in GER-RF. It can be expressed as follows:

$$
L^{\prime}=L_{3 \max }-L_{5},
$$

where $L^{\prime}$ is the reasonable cyclic filling length in GER-RF, $L_{3 \max }$ is the maximum length of the lagging unsupported roof in GER-RF, and $L_{5}$ is the minimum width of the pedestrian passage.

Figure 5 shows the realization process of determining the cyclic filling length in GER-RF based on the stress difference method.

\section{Engineering Analysis}

\subsection{GER of the \#1103 Working Face in Heilong Coal Mine} (Thin Coal Seam)

5.1.1. Project Overview. The \#1103 working face in Heilong Coal Mine in Puxian County of Shanxi Province has an average thickness of $1.3 \mathrm{~m}$ and a buried depth of $210 \mathrm{~m}$. The coal seam dip angle is $0 \sim 20^{\circ}$, with an average $10^{\circ}$. The coal seam contains no gangue, simple structure, and stable layer. With the \#1103 working face as the low-gas face, the self- ignition orientation of coal is classified into level II. The \#1103 working face mining engineering plan is shown in Figure 6(a), and the comprehensive column chart of the coal seam and roof and floor of the \#1103 working face is shown in Figure 6(b).

The designed length of the \#1103 working face is $150 \mathrm{~m}$, and the \#1103 transport roadway opening is in the main transport roadway of the No. 2 coal seam, with a designed length of $531.4 \mathrm{~m}$. The \#1103 transport roadway is used as the air-return roadway of the \#1105 working face after GER. The \#1103 transport roadway section is a rectangular section with width $\times$ height $4.0 \mathrm{~m} \times 2.3 \mathrm{~m}$. It is tunneled along the roof of the coal seam and supported by rock bolts, anchor cables, and metal meshes $[19,20]$. The roof in the roadway is supported by a left-hand screw thread steel bolt of $\Phi 18 \mathrm{~mm} \times L 2.0 \mathrm{~m}$, and the row spacing of anchor bolts is $0.9 \mathrm{~m} \times 1.0 \mathrm{~m}$. The prestressed anchor cable of $\Phi$ $17.8 \mathrm{~mm} \times L 6.3 \mathrm{~m}$ is used for roof support, and the row spacing between anchor cables is $2.0 \mathrm{~m} \times 3.0 \mathrm{~m}$. Three $\Phi$ $18 \mathrm{~mm} \times L 2.0 \mathrm{~m}$ deformed steel bars are arranged on both sides of the roadway, and the spacing between rows is $0.9 \mathrm{~m} \times 1.0 \mathrm{~m}$.

The end hydraulic support of the \#1103 working face is ZT4000/14/30, the length of the top beam of the hydraulic support is $5.5 \mathrm{~m}$, and the supporting strength is $0.6 \mathrm{MPa}$. The cutting depth of the coal cutter is $0.6 \mathrm{~m}$, and the working face periodic weighting length of the main roof is $15 \mathrm{~m}$. The thickness of the immediate roof is $4.5 \mathrm{~m}$, the tensile strength is $0.35 \mathrm{MPa}$, and the compressive strength is $16.1 \mathrm{MPa}$. The roadside filling body of \#1103 transport roadway is constructed with high water quick-setting materials and watercement ratio of $1.5: 1$, with a width of $1.2 \mathrm{~m}$. In order to facilitate the construction of the roadside filling body, the minimum pedestrian width behind the end hydraulic support is $0.8 \mathrm{~m}$.

At the same time, a row of $\Phi 18.9 \mathrm{~mm} \times L 6.3 \mathrm{~m}$ anchor cables are added in the middle of the two rows of roadway roof bolts without anchor cables, and the row spacing is $2.0 \mathrm{~m} \times 1.0 \mathrm{~m}$. A row of $\Phi 8 \mathrm{~mm} \times L 2.0 \mathrm{~m}$ bolts are added in the middle of the two rows of roadway rib bolts. The single hydraulic prop and type steel beam are used to reinforce the retained roadway within the $80 \mathrm{~m}$ range behind the working face, and the column row spacing is $1.2 \mathrm{~m} \times 1.0 \mathrm{~m}$.

5.1.2. Determining the Cyclic Filling Length in GER-RF of the \#1103 Working Face. According to the abovementioned comprehensive column chart, the overburden thickness can be determined to be $14.5 \mathrm{~m}(4.5 \mathrm{~m}+10 \mathrm{~m})$, the average bulk density is $2.5 \mathrm{t} / \mathrm{m}^{3}$, and the load of the overburden rock layer is $0.3625 \mathrm{MPa}$. According to that mentioned above, $L_{1}=10 \mathrm{~m}, L_{2}=5.5 \mathrm{~m}$, and $L_{3}+L_{4}=15 \mathrm{~m}$. By substituting the abovementioned data into the calculation, the immediate roof horizontal stress distribution cloud map of the retained roadway with different lengths of the lagging unsupported roof is obtained, as shown in Figure 7.

According to Figure 7, the horizontal stress distribution of the immediate roof of the retained roadway with different lengths of the lagging unsupported roof is as follows: 


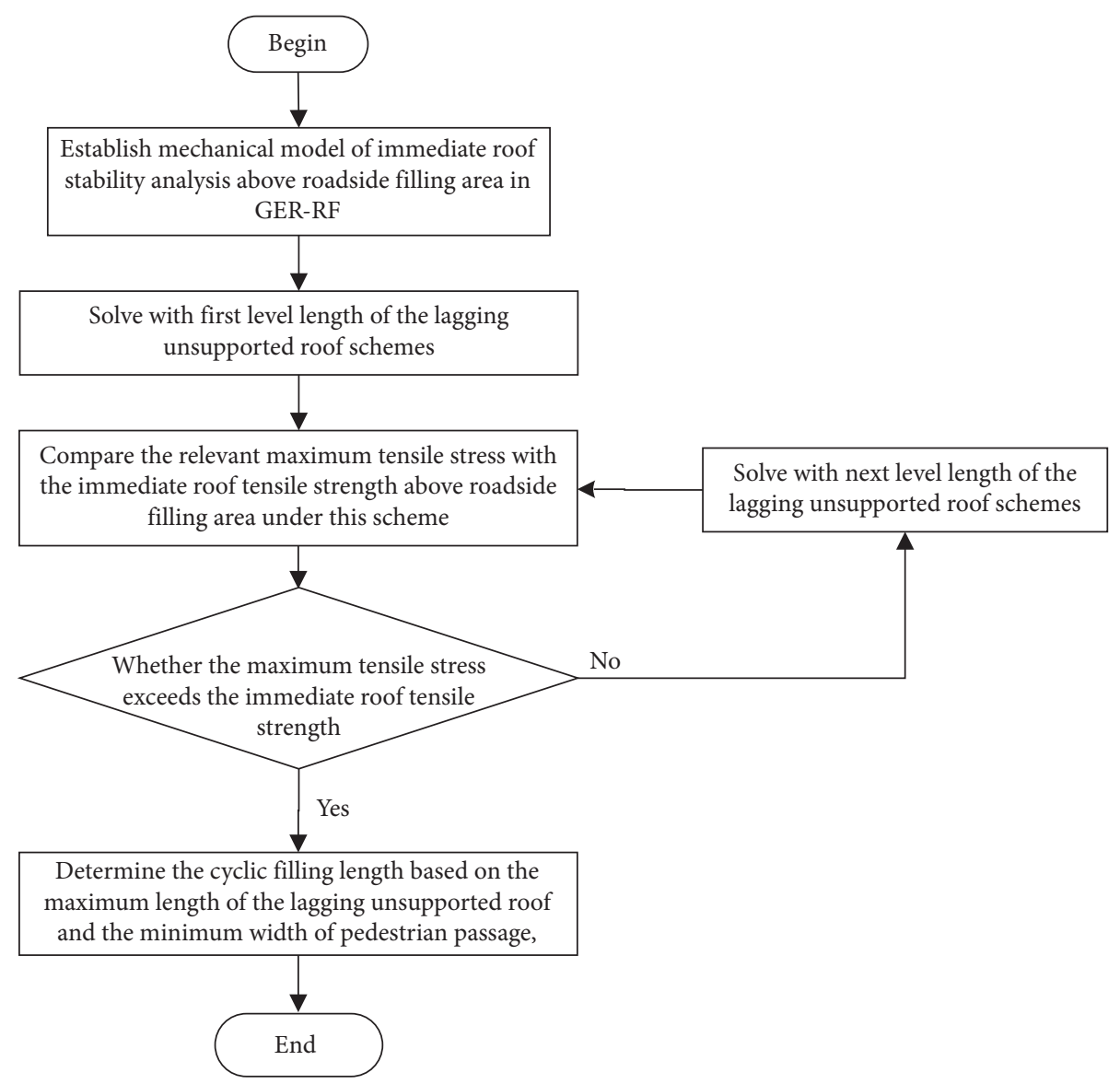

Figure 5: Calculation flow of the cyclic backfill length of GER-BB based on the stress difference method.

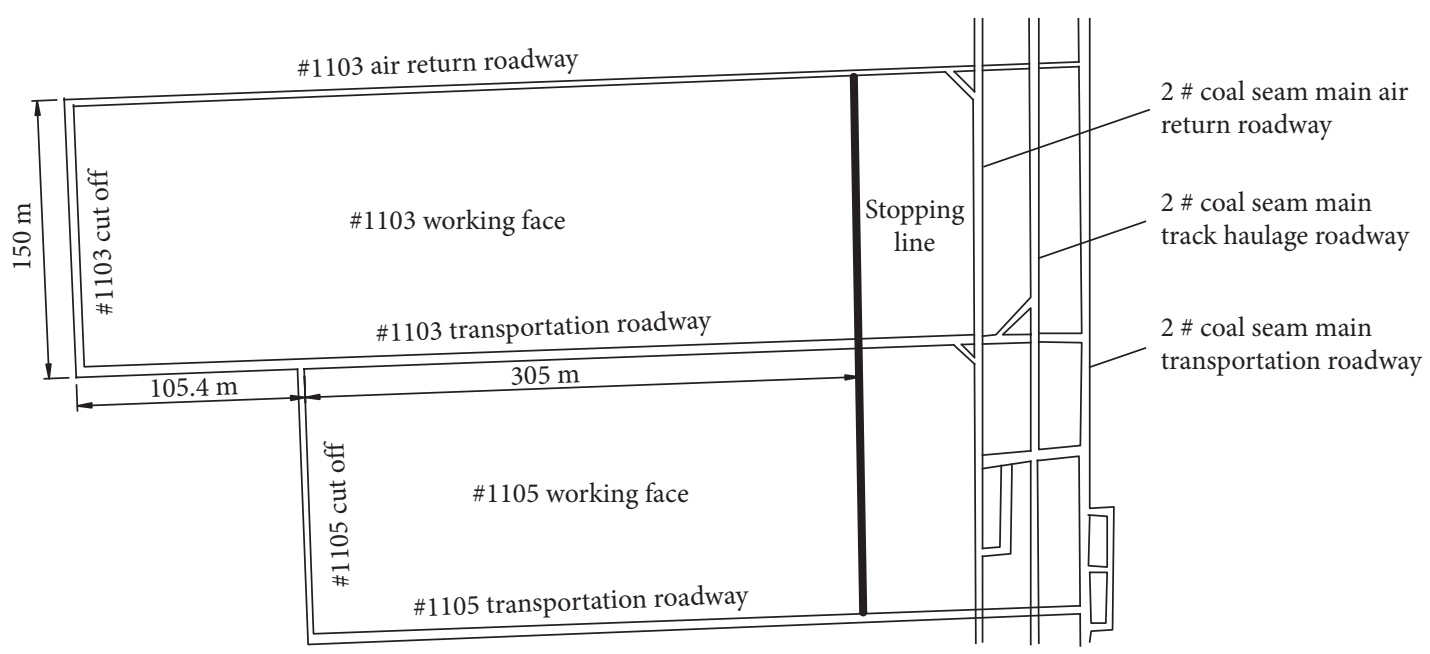

(a)

Figure 6: Continued. 


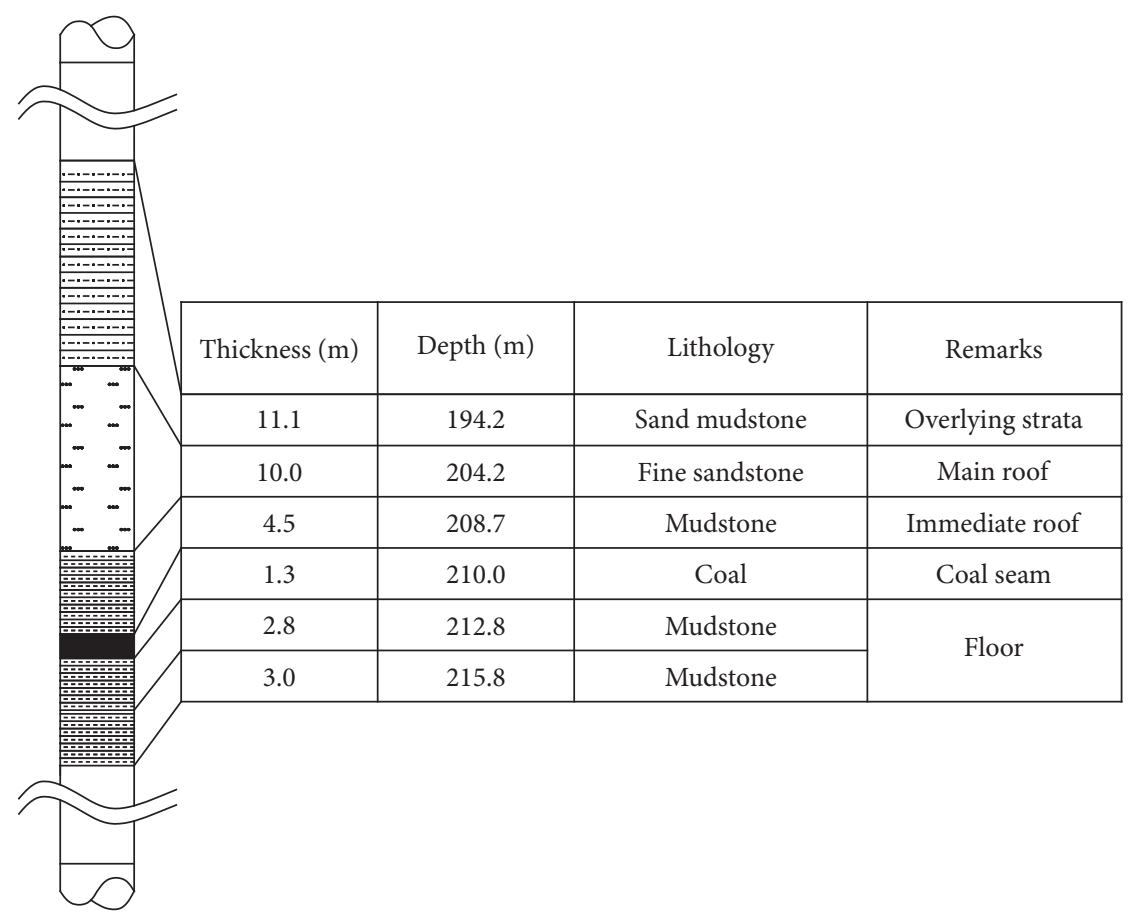

(b)

FIGURE 6: Geological conditions of production at the \#1103 working face in Heilong Coal Mine. (a) Mining plan of the \#1103 working face. (b) Comprehensive column chart of the coal seam and roof and floor of the \#1103 working face.

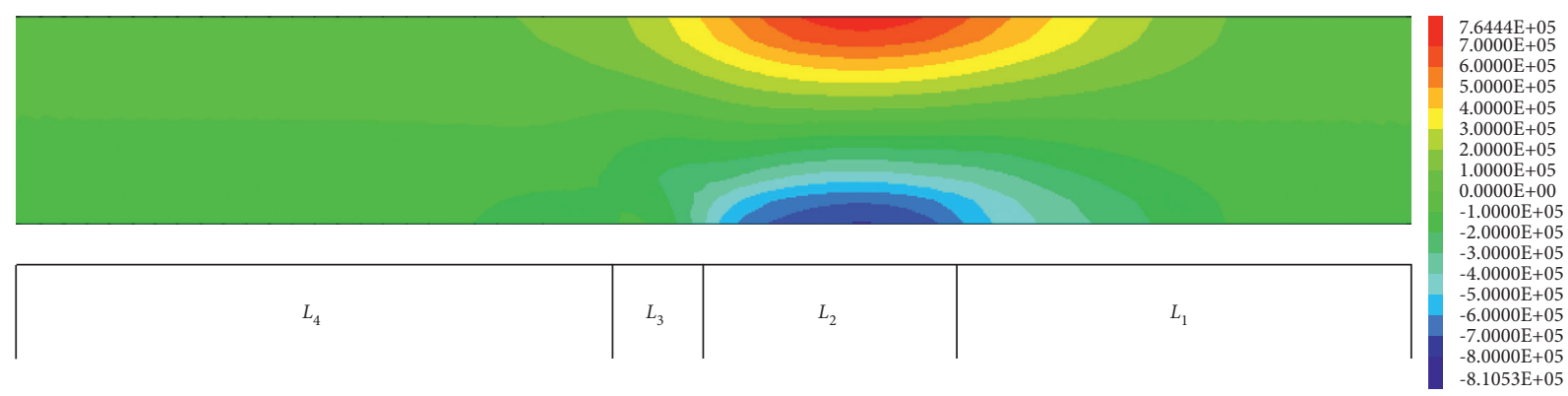

(a)

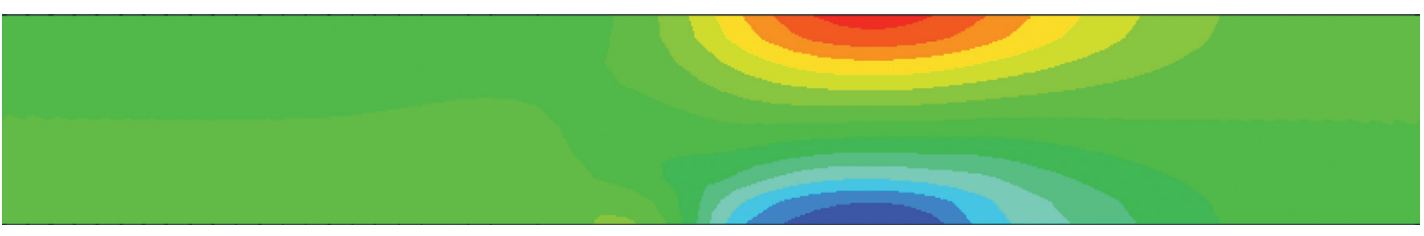

$6.5524 \mathrm{E}+05$
$6.0000 \mathrm{E}+05$
$5.0005+05$ $6.0000 \mathrm{E}+05$ $5.0000 \mathrm{E}+05$ $4.0000 \mathrm{E}+05$ $3.0000 \mathrm{E}+05$ $2.0000 \mathrm{E}+05$ $1.0000 \mathrm{E}+05$ $0.0000 \mathrm{E}+00$ $-1.0000 \mathrm{E}+05$ $-2.0000 \mathrm{E}+05$ $-3.0000 \mathrm{E}+05$ $-4.0000 \mathrm{E}+05$
$-5.0000 \mathrm{E}+05$

$-5.0000 \mathrm{E}+05$

$-6.0000 \mathrm{E}+05$

$-7.0000 \mathrm{E}+05$
$-7.0231 \mathrm{E}+05$

(b)

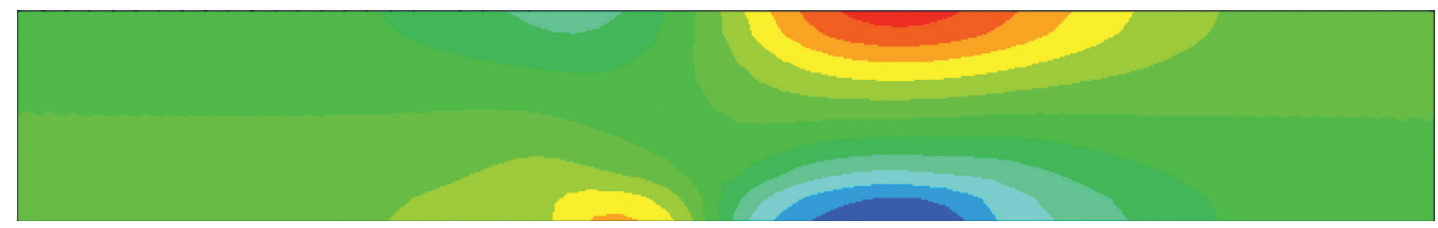




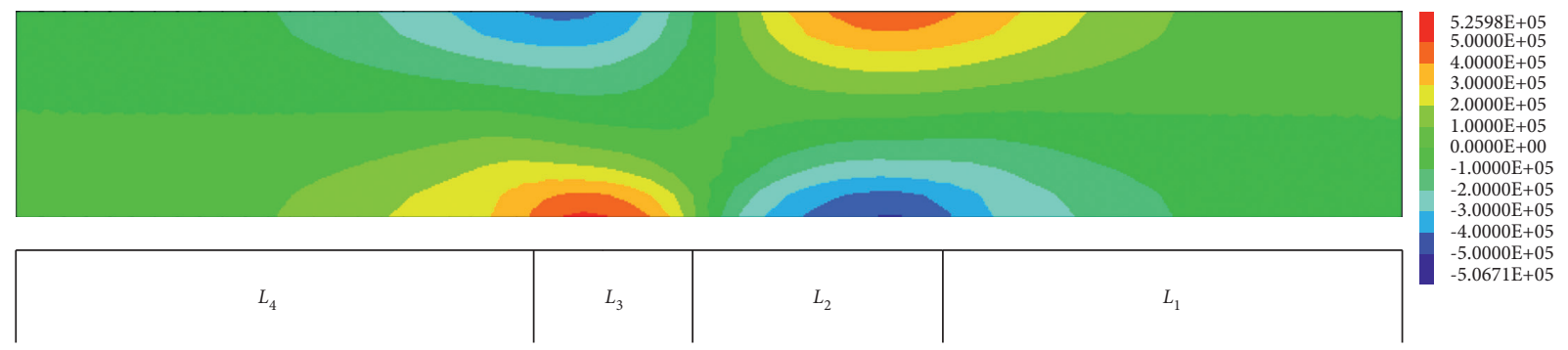

(d)

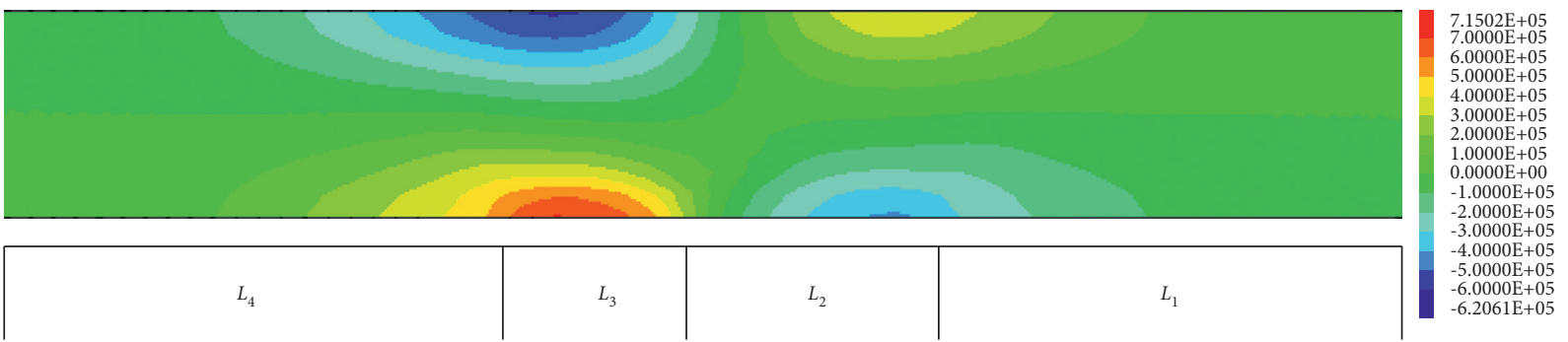

(e)

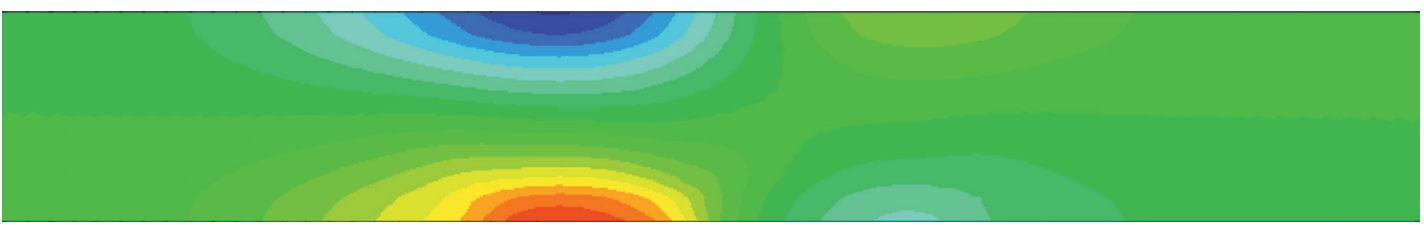

(f)

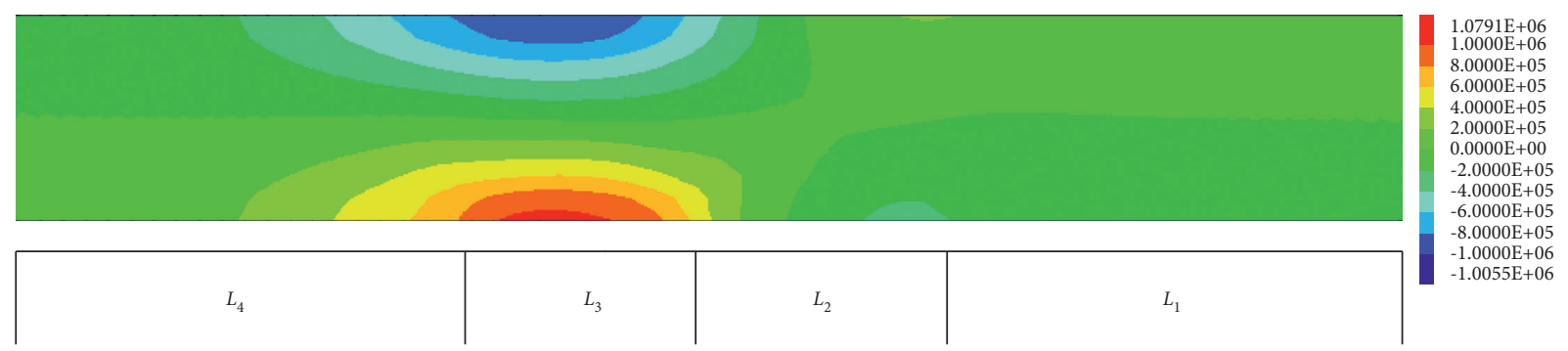

(g)

FIGURE 7: Immediate roof horizontal stress distribution cloud map of the retained roadway with different lengths of the lagging unsupported roof (unit: Pa). (a) Length of the lagging unsupported roof is $2.0 \mathrm{~m}$. (b) Length of the lagging unsupported roof is $2.5 \mathrm{~m}$. (c) Length of the lagging unsupported roof is $3.0 \mathrm{~m}$. (d) Length of the lagging unsupported roof is $3.5 \mathrm{~m}$. (e) Length of the lagging unsupported roof is $4.0 \mathrm{~m}$. (f) Length of the lagging unsupported roof is $4.5 \mathrm{~m}$. (g) Length of the lagging unsupported roof is $5.0 \mathrm{~m}$.

(1) When the length of the lagging unsupported roof is no more than $2.5 \mathrm{~m}$, the upper immediate roof rock is subjected to the tensile stress, while the lower immediate roof rock is subjected to the compressive stress. The maximum compressive stress occurs in the middle of the immediate roof bottom boundary of the end hydraulic support section, and the maximum tensile stress occurs in the middle of the immediate roof boundary of the end hydraulic support section.
(2) When the length of the lagging unsupported roof is greater than $2.5 \mathrm{~m}$ and less than $4.5 \mathrm{~m}$, the upper immediate roof rock above the unsupported area is subjected to compressive stress and the lower immediate roof rock above the unsupported area is subjected to tensile stress. The upper immediate roof rock above the end hydraulic support is subjected to compressive stress, and the lower immediate roof rock above the end hydraulic support is subjected to tensile stress. 
(3) When the length of the lagging unsupported roof is greater than $4.5 \mathrm{~m}$, the upper immediate roof rock is subjected to compressive stress and the lower immediate roof rock is subjected to tensile stress. The maximum tensile stress occurs in the middle of the lower boundary above the unsupported area, and the maximum compressive stress occurs in the middle of the upper boundary above the unsupported area.

With the increase of the length of the lagging unsupported roof, the maximum tensile stress at the lower part of the immediate roof above the unsupported area gradually increases, and the detailed results are shown in Table 1.

According to the aforementioned immediate roof tensile strength of $0.35 \mathrm{MPa}$, when the length of the lagging unsupported roof is no less than $3.5 \mathrm{~m}$ (cyclic filling length is no less than $2.7 \mathrm{~m}$ ), the lower immediate roof rock above the roadside filling area is subjected to the tensile stress. Taking integer times of the coal cutter cutting depth, the rational cyclic filling length is $2.4 \mathrm{~m}$.

5.1.3. Model Validation and Implementation Effect. No caving or other instability failure occurred in the filling area during the implementation of GER-RF. This indicates that the cyclic filling length and the length of the lagging unsupported roof are appropriate and the proposed model is rational. The in situ monitoring results show that the surrounding rock deformation of the retained roadway tends to be stable $80 \mathrm{~m}$ behind the \#1103 working face, the maximum displacement of the roof to floor is $1429.6 \mathrm{~mm}$, and the displacement of two ribs is not more than $490.1 \mathrm{~mm}$.

Figure 8 shows the implementation effect of GER-RF in Heilong Coal Mine. The abovementioned monitoring shows that the surrounding rock of the retained roadway is basically intact after GER-RF, which meets the expected requirements, and the cyclic filling length of the roadside filling body determined by the study meets the requirements for ensuring safe construction of GER-RF.

\subsection{GER of the \#1301 Working Face in Licun Coal Mine (Thick Coal Seam)}

5.2.1. Project Overview. Licun Coal Mine is located in Changzhi City, Shanxi Province, with a designed production capacity of 3.0 million tons per year. There are three coal seams in the mine, of which No. 3 and No. 15 coal seams are the main coal seams. No. 3 coal seam is the high-gassy coal seam with outburst. The \#1301 working face is the first mining working face of the mine, without mining activities all around. The average coal thickness is $4.2 \mathrm{~m}$, the average dip angle is $3^{\circ}$, and the buried depth is $597 \mathrm{~m} 561 \mathrm{~m}$. Figure 9(a) shows the excavation plan of the \#1301 working face. Figure 9(b) shows the comprehensive column chart of the coal seam and roof and floor of the \#1301 working face.

The section of the \#1301 transportation roadway is a rectangular section with width $\times$ height $=5.5 \mathrm{~m} \times 4.0 \mathrm{~m}$. The roadway is driven along the roof of the coal seam and supported by bolts, metal meshes, and anchor cables. The width of coal pillars in the section is $25 \mathrm{~m}$. The roof of the \#1301 transportation roadway consists of seven $\Phi 22 \mathrm{~mm} \times L$ $2.4 \mathrm{~m}$ screw thread steel bolts with a row spacing of $0.8 \mathrm{~m} \times 0.9 \mathrm{~m}$; the row spacing of anchor cables at the roof is $2.0 \mathrm{~m} \times 1.8 \mathrm{~m}$, and the length of anchor cables is $7.3 \mathrm{~m}$. The anchor cables are arranged symmetrically along the center line of the roadway. Two ribs are supported by $\Phi 22 \mathrm{~mm} \times L$ $2.4 \mathrm{~m}$ high-strength deformed steel bolts with a row spacing of $0.9 \mathrm{~m} \times 0.9 \mathrm{~m}$.

In order to further meet the needs of mining replacement and gas treatment and improve the recovery rate of highquality coal, the \#1301 transportation roadway is retained as the mining roadway of the \#1303 working face. The end hydraulic support of the \#1301 working face is ZY13000/28/ $62 \mathrm{D}$, the length of the top beam of the hydraulic support is $5.5 \mathrm{~m}$, and the support strength is $1.1 \mathrm{MPa}$. The periodic weighting length of the main roof is $20 \mathrm{~m}$, the immediate roof thickness is $3.5 \mathrm{~m}$, the tensile strength is $1.5 \mathrm{MPa}$, the compressive strength is $12.8-33.6 \mathrm{MPa}$, and the cutting depth of the coal cutter is $0.8 \mathrm{~m}$.

The roadside filling body \#1301 transport roadway is constructed with high water quick-setting materials and a water-cement ratio of $1.5: 1$, with a width of $2.5 \mathrm{~m}$. The minimum pedestrian width behind the end hydraulic support is $0.8 \mathrm{~m}$. Two rows of $\Phi 18.9 \mathrm{~mm} \times L 7.3 \mathrm{~m}$ anchor cables are added in the middle of the two rows of roadway roof anchor cables, and the row spacing is $2.0 \mathrm{~m} \times 1.8 \mathrm{~m}$. Two rows of $\Phi 18.9 \mathrm{~mm} \times L 4.3 \mathrm{~m}$ anchor cables are added in the middle of the two rows of roadway solid coal rib bolts, and the row spacing is $1.5 \mathrm{~m} \times 0.9 \mathrm{~m}$. The single hydraulic prop and type steel beam are used to reinforce the retained roadway within the $100 \mathrm{~m}$ range behind the working face, and the column row spacing is $1.0 \mathrm{~m} \times 1.0 \mathrm{~m}$. In order to prevent roof falling and layer separation above the roadside filling area, a polyester fiber mesh is laid in front of 5 hydraulic supports in the end area. At the same time, a row of $\Phi 22 \mathrm{~mm} \times L 2.4 \mathrm{~m}$ bolts are installed with a row spacing of $0.8 \mathrm{~m} \times 0.8 \mathrm{~m}$. $\Phi 18.9 \mathrm{~mm} \times L 4.3 \mathrm{~m}$ anchor cables are drilled every two rows of bolts behind the end hydraulic support, with a row spacing of $1.5 \mathrm{~m} \times 1.6 \mathrm{~m}$.

5.2.2. Determining the Cyclic Filling Length in GER-RF of the \#1301 Working Face. According to the abovementioned comprehensive column chart, the overburden thickness can be determined to be $23.6 \mathrm{~m}(3.5 \mathrm{~m}+4 \mathrm{~m}+9.9 \mathrm{~m}+6.2 \mathrm{~m})$, the average bulk density is $2.5 \mathrm{t} / \mathrm{m}^{3}$, and the load of the overburden rock layer is $0.59 \mathrm{MPa}$. According to that mentioned above, $L_{1}=10 \mathrm{~m}, L_{2}=5.5 \mathrm{~m}$, and $L_{3}+L_{4}=20 \mathrm{~m}$. By substituting the abovementioned data into the calculation, the immediate roof horizontal stress distribution cloud map of the retained roadway with different lengths of the lagging unsupported roof is obtained, as shown in Figure 10.

According to Figure 10, the horizontal stress distribution of the immediate roof of the retained roadway with different lengths of the lagging unsupported roof is as follows:

(1) When the length of the lagging unsupported roof is no more than $3.0 \mathrm{~m}$, the upper immediate roof rock 
TABLE 1: Maximum tensile stress of the lower immediate roof in GER-RF with respect to the length of the lagging unsupported roof and cyclic filling length.

\begin{tabular}{lcc}
\hline Length of the lagging unsupported roof $(\mathrm{m})$ & Cyclic filling length $(\mathrm{m})$ & Maximum tensile stress $(\mathrm{MPa})$ \\
\hline 2.0 & 1.2 & -0.095 (in this case, compressive stress) \\
2.5 & 1.7 & 0.12 \\
3.0 & 2.2 & 0.32 \\
3.5 & 2.7 & 0.52 \\
4.0 & 3.2 & 0.72 \\
4.5 & 3.7 & 0.9 \\
5.0 & 4.2 & 1.08 \\
\hline
\end{tabular}
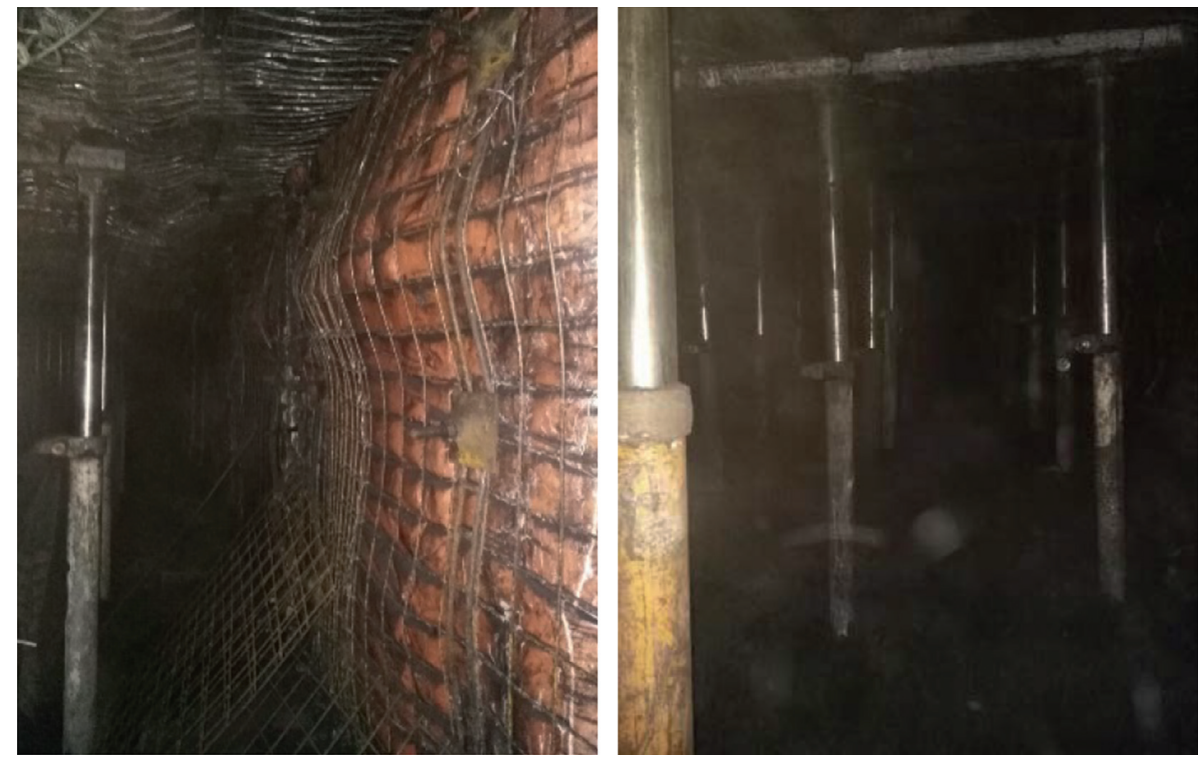

FIGURE 8: GER implementation effect of the \#1103 working face in Heilong Coal Mine.

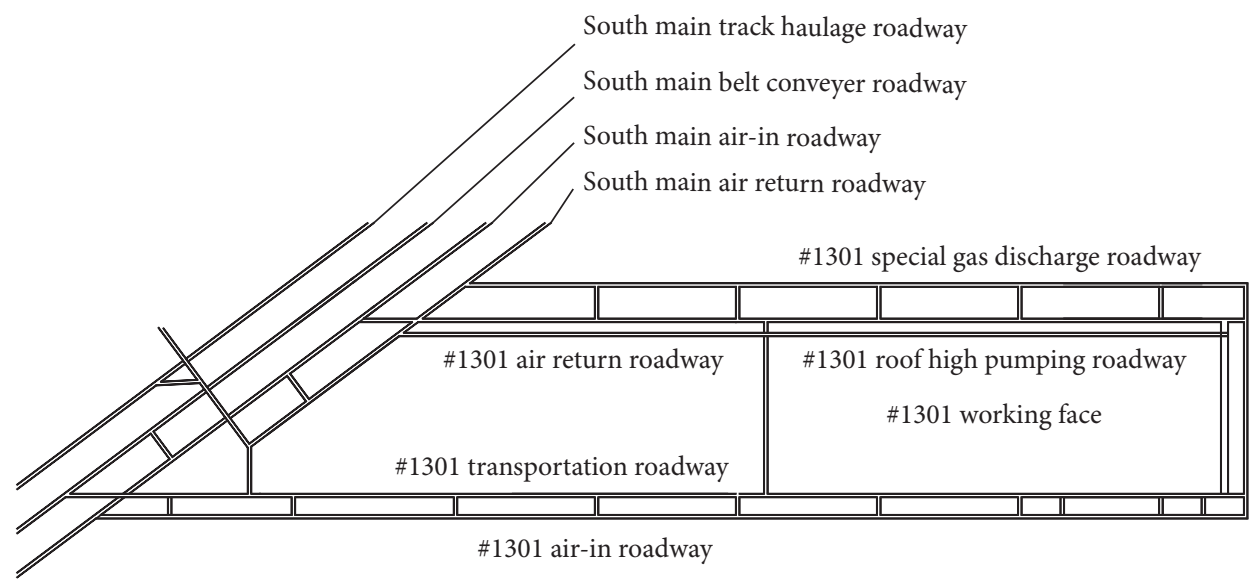

(a)

Figure 9: Continued. 


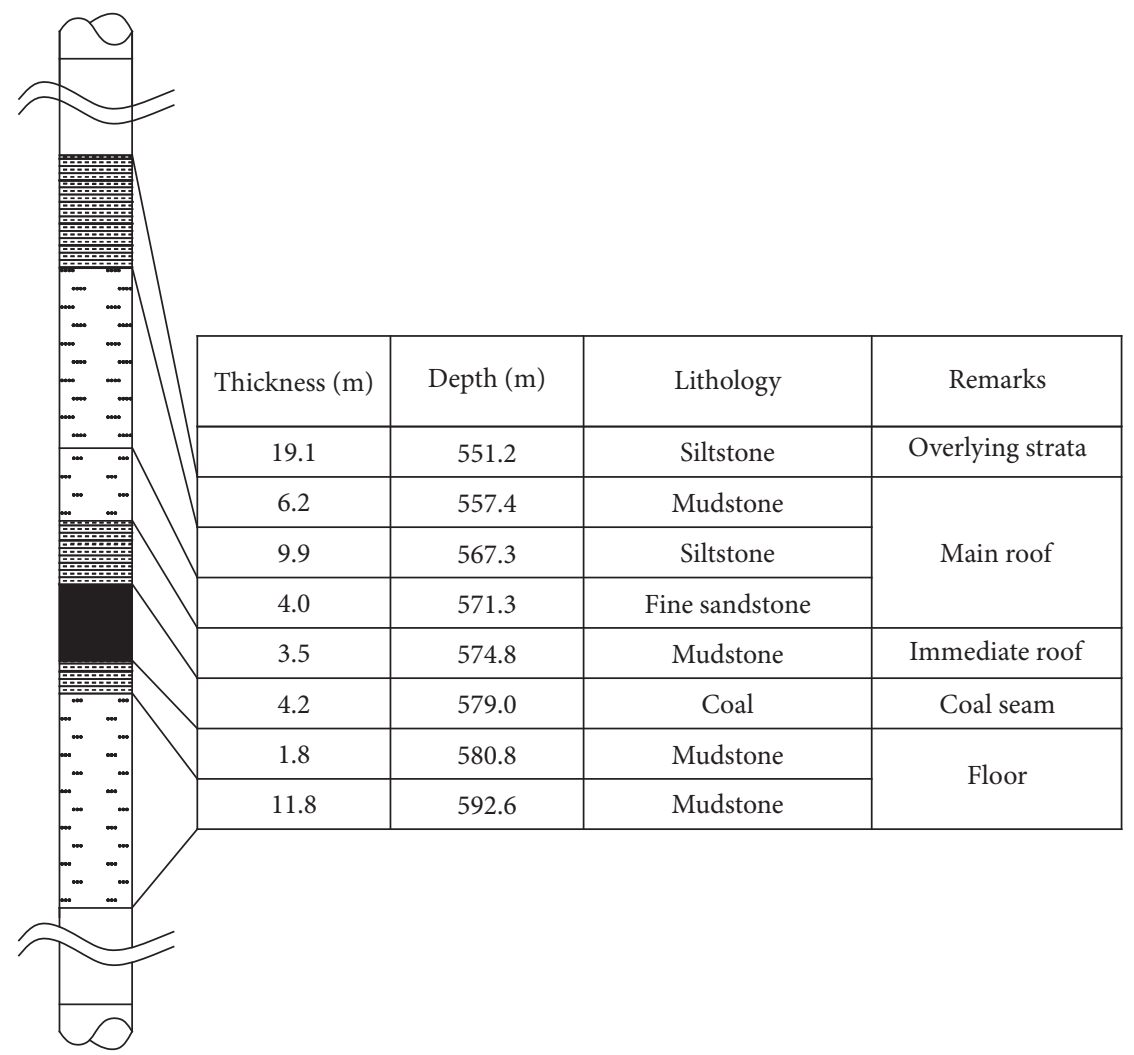

(b)

FIGURE 9: General mining and geology conditions of the \#1301 working face in Licun Coal Mine. (a) Excavation plan of the \#1301 working face. (b) Comprehensive column chart of the coal seam and roof and floor of the \#1301 working face.
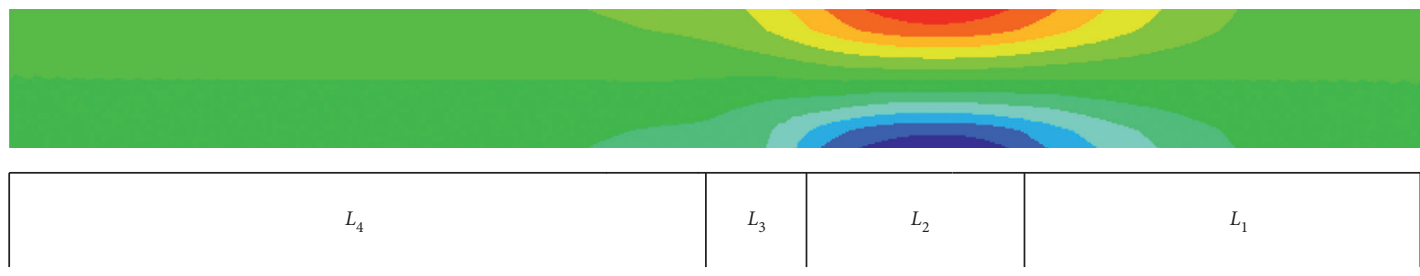

(a)
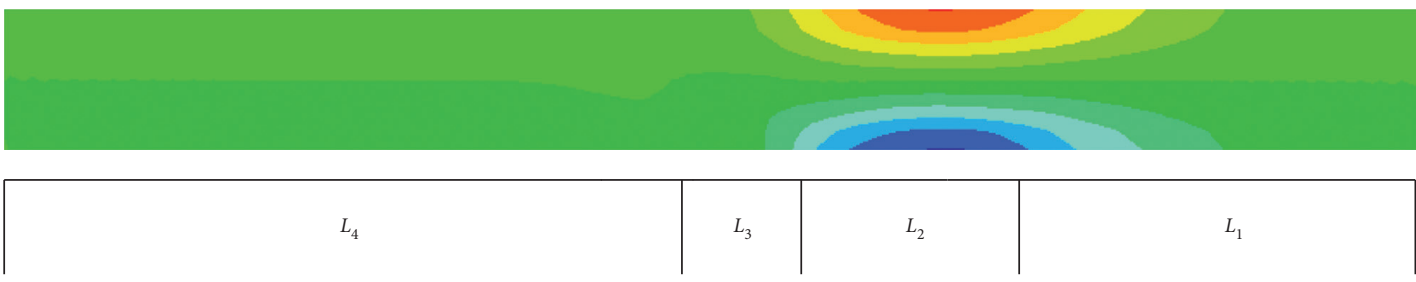

(b)
$2.8553 \mathrm{E}+06$ $2.5000 \mathrm{E}+06$ $2.0000 \mathrm{E}+06$ $1.5000 \mathrm{E}+06$ $1.0000 \mathrm{E}+06$ $5.0000 \mathrm{E}+05$ $0.0000 \mathrm{E}+00$ $-5.0000 \mathrm{E}+05$ $-1.0000 \mathrm{E}+06$ $-1.5000 \mathrm{E}+06$ $-2.0000 \mathrm{E}+06$

$-2.5000 \mathrm{E}+06$

$-2.5000 \mathrm{E}+06$
$-2.9027 \mathrm{E}+06$

$2.5191 \mathrm{E}+06$ $2.5000 \mathrm{E}+06$ $2.0000 \mathrm{E}+06$ $1.5000 \mathrm{E}+06$ $1.0000 \mathrm{E}+06$ $5.0000 \mathrm{E}+05$ $0.0000 \mathrm{E}+00$ $-5.0000 \mathrm{E}+05$ $-1.0000 \mathrm{E}+06$

$-1.5000 \mathrm{E}+06$ $-2.0000 \mathrm{E}+06$ $-2.5000 \mathrm{E}+06$ $-2.5655 \mathrm{E}+06$

Figure 10: Continued. 


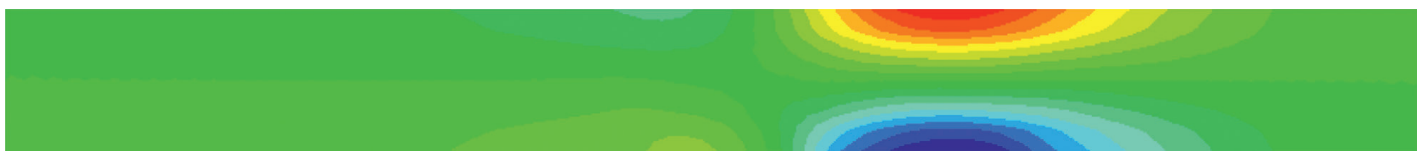

$2.5000 \mathrm{E}+05$

$0.0000 \mathrm{E}+00$

$-2.5000 \mathrm{E}+05$

$-5.0000 \mathrm{E}+05$

$-7.5000 \mathrm{E}+05$

$-1.0000 \mathrm{E}+06$

$-1.2500 \mathrm{E}+06$

$-1.5000 \mathrm{E}+06$

$-1.7500 \mathrm{E}+06$

$-2.0000 \mathrm{E}+06$

$-2.2471 \mathrm{E}+06$

(c)

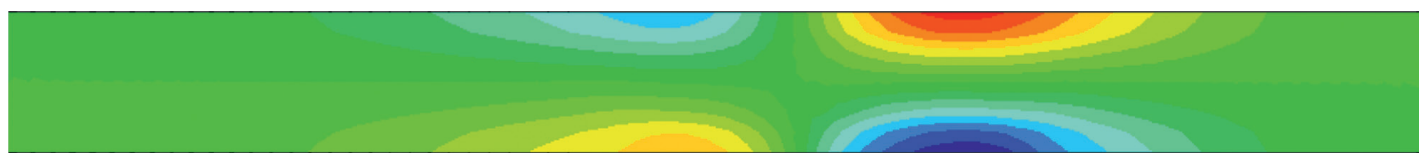

$1.8883 \mathrm{E}+06$

$1.7500 \mathrm{E}+06$

$1.5000 \mathrm{E}+06$

$1.2500 \mathrm{E}+06$

$1.0000 \mathrm{E}+06$

$7.5000 \mathrm{E}+05$

$5.0000 \mathrm{E}+05$

$2.5000 \mathrm{E}+05$

$0.0000 \mathrm{E}+00$

$-2.5000 \mathrm{E}+05$

$-5.0000 \mathrm{E}+05$

$-7.5000 \mathrm{E}+05$

$-1.0000 \mathrm{E}+06$

$-1.2500 \mathrm{E}+06$

$-1.5000 \mathrm{E}+06$

$-1.7500 \mathrm{E}+06$

$-1.9488 \mathrm{E}+06$

(d)

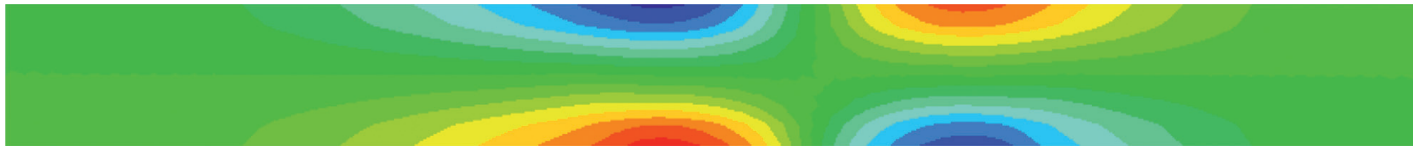

$1.8898 \mathrm{E}+06$ $1.7500 \mathrm{E}+06$

$1.5000 \mathrm{E}+06$

$1.2500 \mathrm{E}+06$

$1.0000 \mathrm{E}+06$

$7.5000 \mathrm{E}+05$

$5.0000 \mathrm{E}+05$

$2.5000 \mathrm{E}+05$

$0.0000 \mathrm{E}+00$

$-2.5000 \mathrm{E}+05$

$-5.0000 \mathrm{E}+05$

$-7.5000 \mathrm{E}+05$

$-1.0000 \mathrm{E}+06$

$-1.2500 \mathrm{E}+06$

$-1.5000 \mathrm{E}+06$

$-1.7500 \mathrm{E}+06$

$-1.7992 \mathrm{E}+06$

(e)

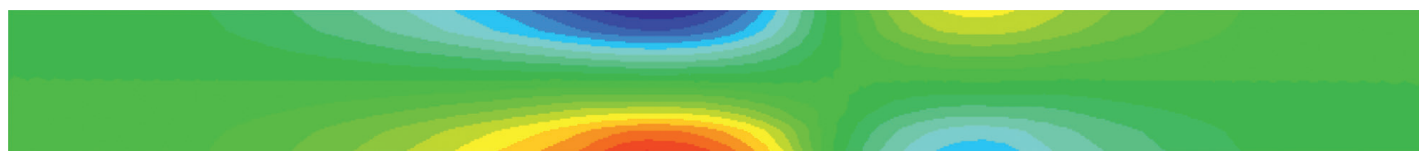

$12500 \mathrm{E}+06$

$7.5000 \mathrm{E}+05$

$2.5000 \mathrm{E}+05$

$-2.5000 \mathrm{E}+05$

$-7.5000 \mathrm{E}+05$

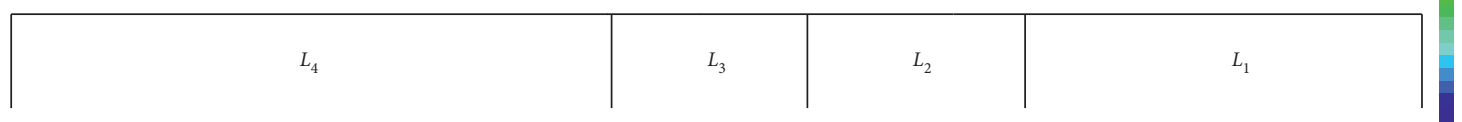

$1.2500 \mathrm{E}+06$

$-1.7500 \mathrm{E}+06$

$-2.2500 \mathrm{E}+06$

$-2.4179 \mathrm{E}+06$

(f)

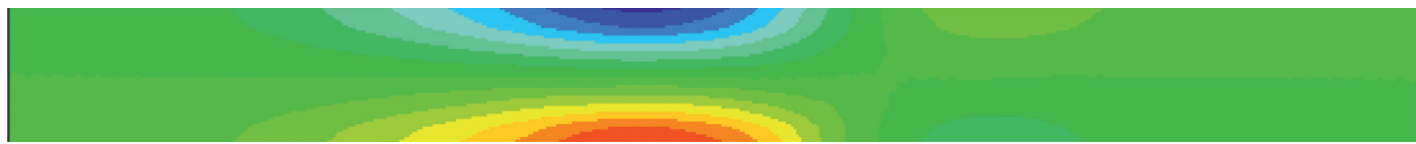

$3.7006 \mathrm{E}+06$

$3.5000 \mathrm{E}+06$
$3.0000 \mathrm{E}+06$

$3.0000 \mathrm{E}+06$
$2.5000 \mathrm{E}+06$

$2.5000 \mathrm{E}+06$

$2.0000 \mathrm{E}+06$

$1.5000 \mathrm{E}+06$

$1.0000 \mathrm{E}+06$

$5.0000 \mathrm{E}+05$

$0.0000 \mathrm{E}+00$

$-5.0000 \mathrm{E}+05$
$-1.0000 \mathrm{E}+06$

$-1.0000 \mathrm{E}+06$
$-1.5000 \mathrm{E}+06$

$-2.0000 \mathrm{E}+06$

$-2.5000 \mathrm{E}+06$

$-3.0000 \mathrm{E}+06$

$-3.0000 \mathrm{E}+06$
$-3.5000 \mathrm{E}+06$

$-3.5000 \mathrm{E}+06$
$-3.6563 \mathrm{E}+06$

(g)

Figure 10: Continued. 


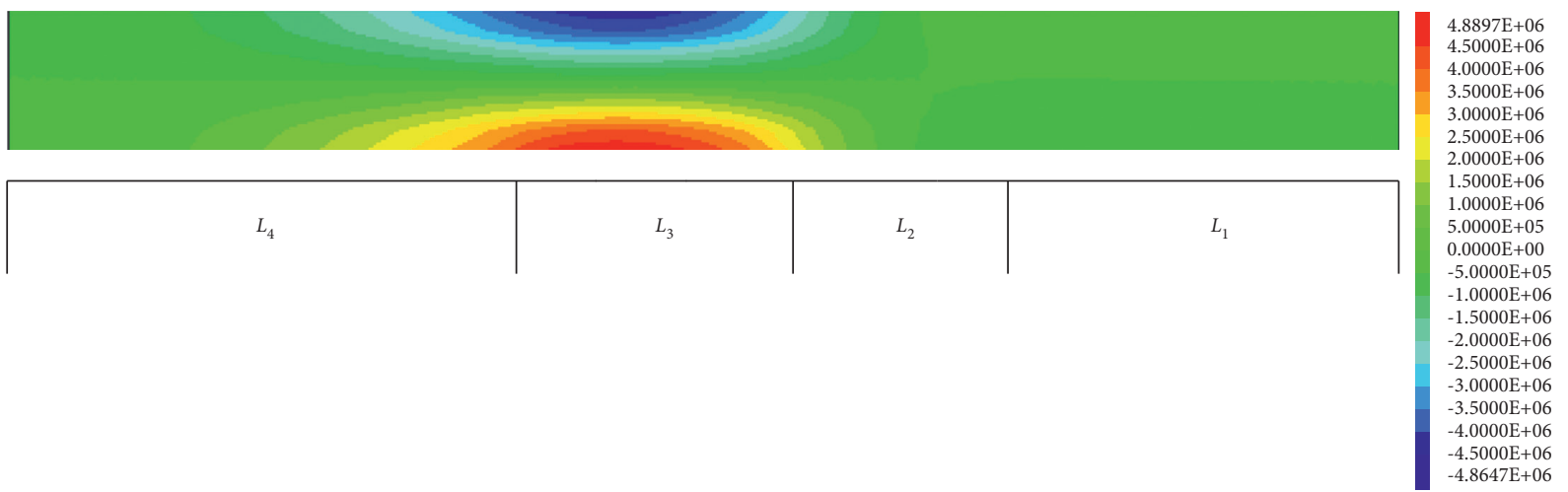

(h)

FiguRe 10: Immediate roof horizontal stress distribution cloud map of the retained roadway with different lengths of the lagging unsupported roof (unit: Pa). (a) $2.5 \mathrm{~m}$. (b) $3.0 \mathrm{~m}$. (c) $3.5 \mathrm{~m}$. (d) $4.0 \mathrm{~m}$. (e) $4.5 \mathrm{~m}$. (f) $5.0 \mathrm{~m}$. (g) $6.0 \mathrm{~m}$. (h) $7.0 \mathrm{~m}$.

is subjected to the tensile stress while the lower immediate roof rock is subjected to the compressive stress. The maximum compressive stress occurs in the middle of the immediate roof bottom boundary of the end hydraulic support section, and the maximum tensile stress occurs in the middle of the immediate roof boundary of the end hydraulic support section.

(2) When the length of the lagging unsupported roof is greater than $3.0 \mathrm{~m}$ and less than $7.0 \mathrm{~m}$, the upper immediate roof rock above the unsupported area is subjected to compressive stress and the lower immediate roof rock above the unsupported area is subjected to tensile stress. The upper immediate roof rock above the end hydraulic support is subjected to compressive stress, and the lower immediate roof rock above the end hydraulic support is subjected to tensile stress.

(3) When the length of the lagging unsupported roof is greater than $7.0 \mathrm{~m}$, the upper immediate roof rock is subjected to compressive stress, and the lower immediate roof rock is subjected to tensile stress. The maximum tensile stress occurs in the middle of the lower boundary above the unsupported area, and the maximum compressive stress occurs in the middle of the upper boundary above the unsupported area.

With the increase of the length of the lagging unsupported roof, the maximum tensile stress at the lower part of the immediate roof above the unsupported area gradually increases, and the detailed results are shown in Table 2.

According to the aforementioned immediate roof tensile strength of $1.5 \mathrm{MPa}$, when the length of the lagging unsupported roof is no less than $4.5 \mathrm{~m}$ (cyclic filling length is no less than $3.7 \mathrm{~m}$ ), and the lower immediate roof rock above the roadside filling area is subjected to the tensile stress. Taking integer times of the coal cutter cutting depth, the rational cyclic filling length is $3.2 \mathrm{~m}$.
5.2.3. Model Validation and Implementation Effect. No caving or other instability failure occurred in the filling area during the implementation of GER-RF. This indicates that the cyclic filling length and the length of the lagging unsupported roof are appropriate and the proposed model is rational. The in situ monitoring results show that the surrounding rock deformation of the retained roadway tends to be stable $100 \mathrm{~m}$ behind the $\# 1301$ working face, the maximum displacement of the roof to floor is $710 \mathrm{~mm}$, and the displacement of two ribs is not more than $530 \mathrm{~mm}$.

Figure 11 shows the implementation effect of GER-RF in Licun Coal Mine. The abovementioned monitoring shows that the surrounding rock of the retained roadway is basically intact after GER-RF, which meets the expected requirements, and the cyclic filling length of the roadside filling body determined by the study meets the requirements for ensuring safe construction of GER-RF.

\section{Discussion}

In reality, GER-RF support includes road-in support and roadside support. The determination of the cyclic filling length in GER-RF belongs to roadside support problems. At present, there are no published reports at home and abroad on the determination method and theory of the cyclic filling length in GER-RF. Consequently, a theoretical calculation method to determine the cyclic filling length of GER-RF is firstly provided in this paper. According to the theoretical calculation method, the main influence factors to determine the cyclic filling length of GER-RF include the immediate roof tensile strength, roadside filling body strength, support strength of the end hydraulic support, and production rates.

\subsection{Relationship between the Immediate Roof Tensile Strength} and the Rational Cyclic Filling Length of GER-RF. For Heilong Coal Mine, according to the calculated results shown in Table 2, the relationship between the immediate roof tensile strength and the rational cyclic filling length of GER-RF is shown in Figure 12(a). For Licun Coal Mine, according to 
TABLE 2: Maximum tensile stress of the lower immediate roof in GER-RF with respect to the length of the lagging unsupported roof and cyclic filling length.

\begin{tabular}{lcc}
\hline Length of the lagging unsupported roof $(\mathrm{m})$ & Cyclic filling length $(\mathrm{m})$ & Maximum tensile stress $(\mathrm{MPa})$ \\
\hline 2.5 & 1.7 & -0.72 \\
3.0 & 2.2 & -0.03 \\
3.5 & 2.7 & 0.59 \\
4.0 & 3.2 & 1.25 \\
4.5 & 3.7 & 1.87 \\
5.0 & 4.2 & 2.503 \\
5.5 & 4.7 & 3.114 \\
6.0 & 5.2 & 3.7 \\
6.5 & 5.7 & 4.2993 \\
7.0 & 6.2 & 4.8897 \\
\hline
\end{tabular}

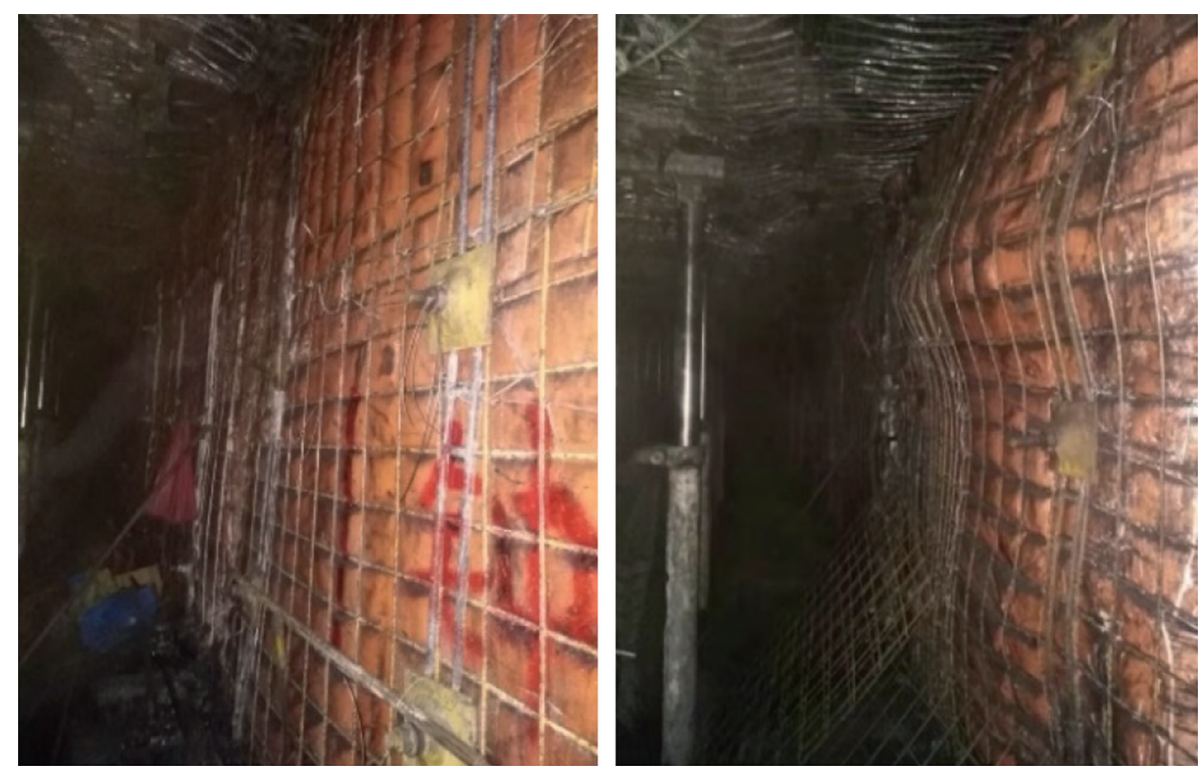

FIGURE 11: GER implementation effect of the \#1301 working face in Licun Coal Mine.

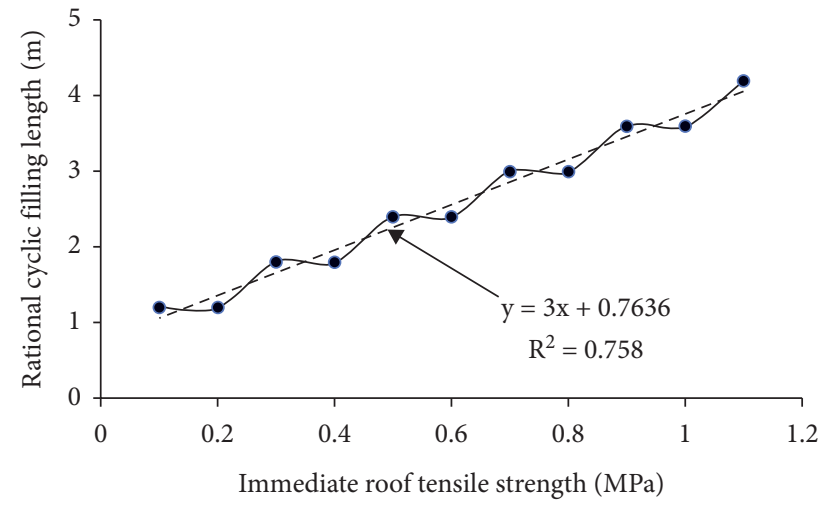

(a)

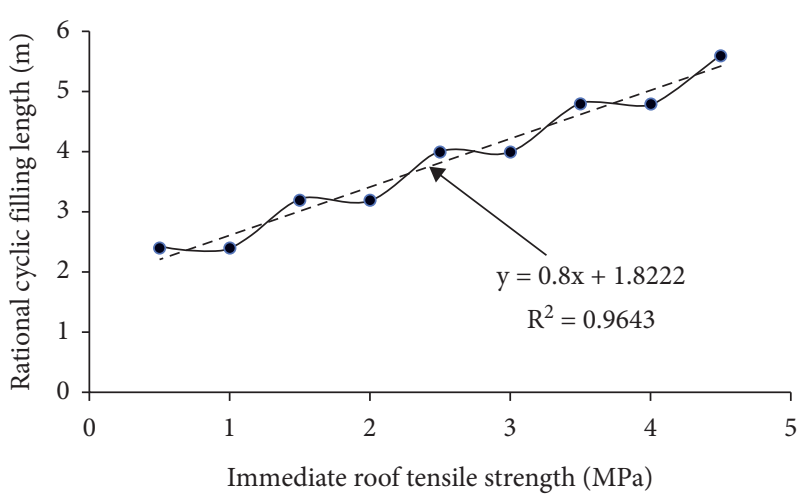

(b)

Figure 12: Relationship between the immediate roof tensile strength and the rational cyclic filling length. (a) Heilong Coal Mine. (b) Licun Coal Mine.

the calculated results shown in Table 2, the relationship between the immediate roof tensile strength and the rational cyclic filling length of GER-RF is shown in Figure 12(b).
As the immediate roof tensile strength increases, the rational cyclic filling length increases. When the immediate roof tensile strength increases, tensile failure is more difficult 
to occur in the immediate roof above the filling area. In addition, the immediate roof maintains integrity before the end hydraulic support moves forward, the rational cyclic filling length would be greater, and the GER-RF operational efficiency would be higher.

6.2. Relationship between the Roadside Filling Body Strength, the Support Strength of the End Hydraulic Support, and the Cyclic Filling Length of GER-RF. Consequently, with the increase of the roadside filling body strength, the tensile failure is more difficult to occur in the immediate roof above the filling area. Research results have shown that the greater the roadside filling body strength, the fewer the main roof rotation angle and the less the tensile stress action range above the filling area. Moreover, the relationship between the support strength of the end hydraulic support and the cyclic filling length of GER-RF presents the same pattern.

6.3. Relationship between the Production Rates and the Cyclic Filling Length of GER-RF. In reality, during the implementation of GER-RF, the rational daily cyclic filling length is greater than the daily working face mining length (production rates). In order to match the daily mining length of the high-efficiency fully mechanized mining working face, the rational cyclic filling length is adjust to the daily production plan and the daily cutting depth of the coal cutter.

\section{Conclusions}

The construction of the roadside filling body is the key to match the GER-RF speed with the mining speed of the highefficiency fully mechanized working face. How to determine the rational cycle filling length of a roadside filling body not only affects consumption of building and removing the formwork of the roadside filling body but also affects the mining process of the fully mechanized working face. At present, there is no theoretical approach to determine the cyclic filling length in GER-RF. In this paper, we establish a plane strain calculation model between the immediate roof and the below support elements based on the GER-RF surrounding rock structure and stress characteristics. Then, a detailed stress difference method is proposed to calculate the stress analytic value of the immediate roof. Finally, according to the relationship between the tensile stress of the immediate roof and its ultimate tensile strength, the rational cyclic fill length of the roadside filling body in GER-RF is obtained. The main conclusions include the following:

(1) The relationship between the distribution of tensile stress in different areas of GER-RF and the length of the lagging unsupported roof are obtained by using the stress difference method to solve the immediate roof stress of GER-RF. Then, the stability of the immediate roof in the area to be filled is determined by comparing the immediate roof stress with the ultimate tensile strength, and the safe length of the lagging unsupported roof and the reasonable cyclic filling length are obtained.
(2) Engineering trial tests carried out in different thickness coal seams (thin coal seam of Heilong Coal Mine and thick coal seam of Licun Coal Mine) indicate that the proposed method to determine the cyclic filling length is rational and validated. This research is beneficial for developing a practical approach to obtain the cyclic filling length in GER-RF and also provides a practical approach to determine the unsupported roof length in the roadway drivage.

\section{Data Availability}

The datasets used or analyzed during the current study are available from the corresponding author on reasonable request.

\section{Disclosure}

An earlier version of this manuscript (DOI: 10.21203/ rs.3.rs-104890/v1) has been presented as a preprint with the following link: https://www.researchsquare.com/article/ rs-104890/v1.

\section{Conflicts of Interest}

The authors declare no conflicts of interest.

\section{Authors' Contributions}

Zizheng Zhang, Jianbiao Bai, and Weijian Yu contributed to the conception of the study; Jinlin Xin, Xianyang Yu, and Min Deng contributed significantly to analysis and manuscript preparation; Zizheng Zhang and Jinlin Xin performed the data analyses and wrote the manuscript; and Xianyang $\mathrm{Yu}$ helped perform the analysis with constructive discussions.

\section{Acknowledgments}

This project was supported by the National Natural Science Foundation of China through Contract No. 51804111, funded by the Open Fund of the State Key Laboratory of Mining Response and Disaster Prevention and Control in Deep Coal Mines, Anhui University of Science and Technology (No. SKLMRDPC20KF08), and the Natural Science Foundation of Hunan Provincial (No. 2020JJ5194).

\section{References}

[1] H. P. Kang, D. L. Niu, Z. Zhang, J. Lin, Z. H. Li, and M. J. Fan, "Deformation characteristics of surrounding rock and supporting technology of gob-side entry retaining in deep coal mine," Chinese Journal of Rock Mechanics and Engineering, vol. 29, pp. 1977-1987, 2010.

[2] C. Han, N. Zhang, J. Xue, J. Kan, and Y. Zhao, "Multiple and long-term disturbance of gob-side entry retaining by grouped roof collapse and an innovative adaptive technology," Rock Mechanics and Rock Engineering, vol. 52, no. 8, pp. 2761-2773, 2019.

[3] Z. Zhang, J. Bai, Y. Chen, and S. Yan, "An innovative approach for gob-side entry retaining in highly gassy fully- 
mechanized longwall top-coal caving," International Journal of Rock Mechanics and Mining Sciences, vol. 80, pp. 1-11, 2015.

[4] H. Y. Yang, Y. B. Liu, S. G. Cao et al., "A caving self-stabilization bearing structure of advancing cutting roof for gobside entry retaining with hard roof stratum," Geomechanics Engineering, vol. 21, pp. 23-33, 2020.

[5] Y. Deng and S. Wang, "Feasibility analysis of gob-side entry retaining on a working face in a steep coal seam," International Journal of Mining Science and Technology, vol. 24, no. 4, pp. 499-503, 2014.

[6] Y. Zhang, J. Tang, D. Xiao, L. Sun, and W. Zhang, "Spontaneous caving and gob-side entry retaining of thin seam with large inclined angle," International Journal of Mining Science and Technology, vol. 24, no. 4, pp. 441-445, 2014.

[7] M. He, Y. Gao, J. Yang, and W. Gong, "An innovative approach for gob-side entry retaining in thick coal seam longwall mining," Energies, vol. 10, no. 11, p. 1785, 2017.

[8] J. G. Ning, X. S. Liu, J. Tan, Q. H. Gu, Y. L. Tan, and J. Wang, "Control mechanisms and design for a "coal-backfill-gangue" support system for coal mine gob-side entry retaining," International Journal of Oil, Gas and Coal Technology, vol. 18, no. $3 / 4$, pp. $444-466,2018$.

[9] H. Luan, Y. Jiang, H. Lin, and G. Li, "Development of a new gob-side entry-retaining approach and its application," Sustainability, vol. 10, no. 2, p. 470, 2018.

[10] Q. Wang, M. He, J. Yang, H. Gao, B. Jiang, and H. Yu, "Study of a no-pillar mining technique with automatically formed gob-side entry retaining for longwall mining in coal mines," International Journal of Rock Mechanics and Mining Sciences, vol. 110, pp. 1-8, 2018.

[11] W. P. Huang, Y. F. Gao, Z. J. Wen, and L. Gao, "Technology of gob-side entry retaining using concrete-filled steel tubular column as roadside supporting," Journal of China University of Mining and Technology, vol. 44, pp. 604-611, 2015.

[12] X. Ma, M. He, J. Wang, Y. Gao, D. Zhu, and Y. Liu, "Mine strata pressure characteristics and mechanisms in gob-side entry retention by roof cutting under medium-thick coal seam and compound roof conditions," Energies, vol. 11, no. 10, p. 2539, 2018.

[13] Z. Zhang, M. Deng, X. Wang, W. Yu, F. Zhang, and V. D. Dao, "Field and numerical investigations on the lower coal seam entry failure analysis under the remnant pillar," Engineering Failure Analysis, vol. 115, Article ID 104638, 2020.

[14] Z. Zhang, J. Bai, X. Yu, W. Yu, M. Deng, and J. Xin, "Determination of cyclic filling length in gob-side entry retained with roadside filling and its application," Preprint, 2020.

[15] X. Zheng and Y. Bai, "Technology of roof supporting at stowing area in deep roadway retained along gob," Coal Mining Technology, vol. 17, pp. 42-45, 2012.

[16] Z. Zhang, M. Deng, J. Bai, X. Yu, Q. Wu, and L. Jiang, "Strain energy evolution and conversion under triaxial unloading confining pressure tests due to gob-side entry retained," International Journal of Rock Mechanics and Mining Sciences, vol. 126, Article ID 104184, 2020.

[17] J. B. Bai, T. Q. Xiao, and L. Li, "Unsupported roof distance determination of roadway excavation using difference method and its application," Journal of China Coal Society, vol. 36, pp. 920-924, 2011.

[18] S. Yan, R. Wang, J. Bai, W. Wu, and D. Elmo, “An alternative approach to determine cycle length of roadway excavation in coal mines," Journal of Ambient Intelligence and Humanized Computing, vol. 11, no. 2, pp. 553-560, 2020.

[19] J. H. Chen, P. Liu, H. B. Zhao, C. Zhang, and J. W. Zhang, "Analytical studying the axial performance of fully encapsulated rock bolts," Engineering Failure Analysis, vol. 128, Article ID 105580, 2021.

[20] Z. Z. Zhang, M. Deng, J. B. Bai, S. Yan, and X. Y. Yu, "Stability control of gob-side entry retained under the gob with close distance coal seams," International Journal of Mining Science and Technology, vol. 31, no. 2, pp. 321-332, 2021. 